\title{
Kontruksi Model Continuous Improvement Pada Pengelolaan Koperasi XYZ Berbasis Green Management Dengan Perspektif Balance Scorecard (Studi Kasus Departemen Ekspansi Angkutan Limbah)
}

\author{
Mohammad Rachman Waluyo ${ }^{1}$, Fourry Handoko ${ }^{2}$, Prima Vitasari ${ }^{3}$ \\ ${ }^{1,2,3)}$ Program Studi Teknik Industri $S$-2, Pascasarjana, Institut Teknologi Nasional Malang \\ ${ }^{1)}$ Email: aanvicenzo@gmail.com
}

\begin{abstract}
Abstrak
Koperasi XYZ termasuk koperasi dengan kategori aset tinggi yaitu di peringkat 233 di dunia, namun belum menerapkan Green Management. Salah satu divisi Koperasi XYZ yaitu Divisi Ekspansi Angkutan Limbah, diharapkan dapat memenuhi 5 kategori Green Management yaitu Pendekatan Pasar, Stakeholder, Efisiensi, dan Reneawble. Strategi perencanaan operasional untuk Green Management menggunakan Balance Scorecard (BSC). Tujuan penelitianini mengetahui pengaruh variabelbalanced scorecard berbasis Green Managementyang berkelanjutan (Continuos Improvement) yang disinergikan denganStructural Equation Modelling (SEM)sebagai sarana perencanaan strategi kedepandalam proses bisnisnya. Penelitian ini menggunakan skala likert dengan sampel100 untuk memenuhimaximum likelihood estimation, dengan merumuskan 5 hipotesis berdasarkan persepktif BSC dan Green Management.Hasil uji model menunjukkan 4 variabel yang signifikan sedangkan 1 tidak signifikan yaknivariabel pembelajaran $\left(\mathrm{X}_{1}\right)$ terhadap Proses Bisnis Internal $\left(\mathrm{Y}_{1}\right)$. Implikasi model simulasi goodness of fitmodifikasi menghasilkan Chi Squaresebesar 155,941, Probabilitas sebesar 0.253, RMSEA sebesar 0.028, GFI sebesar 0.872, AGFI sebesar 0.832 dan TLI sebesar 0.979.Hasil penelitian ini diharapkan management Koperasi XYZ mampu melakukan improvisasi dalam menghadapi persaingan bisnis dengan merujuk model modifikasi di dalam menjalankan proses bisnisnya.
\end{abstract}

Kata Kunci: Balanced scorecard, Continuos Improvement, Sructural Equation Modelling, Green Management. 


\section{Pendahuluan}

Kinerja Koperasi XYZ termasuk kategori bagus dengan aset 1,2 T. Penilaian kinerja organisasi tidak hanya berdasarkan aset tetapi juga menyangkut manajemen. Dalam menghadapi persaingan Masyarakat Ekonomi ASEAN (MEA), manajemen harus mampu bersaing danharus beriorientasi pada sistemGreen Management yang berkelanjutan (Continous Improvement) agar tetap unggul. Koperasi $\mathrm{XYZ}$ mempunyai salah satu unit bisnis yang fokus di bidang ekspansi pengangkutan limbahdengan berorientasi Green sebagaisalah satu komitmen perusahaan terhadap tanggung jawab lingkungan.

Berdasarkan uraian diatas peneliti ingin membuat suatu model yang mengakomodasi perspektif BSC karena merupakan elemen utama yang sudah diterapkan di perusahaan dengan mensinergikan variabel Green Management untuk memberikan gambaran identifikasi peningkatan kinerja yang berkelanjutan (Continuos Improvement) di Koperasi XYZ yang berwawasan Green Management dengan toolsStructural Equation Modelling (SEM). Apabila pengujian modelmenggunakan SEM menunjukan hasil yang baik akan dijadikan dasar pengukuran pada tahun selanjutnya dengan melihat nilai Goodness Of Fit. Menurut Kaplan \& Norton[1],BSC merupakan suatu metode pengukuran kinerja yang fleksibel yang bisa diterapkan untuk badan usaha atau pun organisasi, yang terdiri dari empat perspektif yaitu keuangan, pelanggan, proses bisnis internal, pembelajaran dan pertumbuhan [1].Keempat proses tersebutmenterjemahkan visi, misi dan strategi perusahaan dalam menentukan ukuran kinerja, visi organisasi yang dijabarkan dalam tujuan dan sasaran [1,2]. Untuk variabel dan indikator penelitian ini dapat dilihat pada tabel 1 .

Tabel 1. Variabel Dan Indikator Penelitian

\begin{tabular}{|c|c|c|}
\hline Variabel & $\begin{array}{l}\text { Variabel } \\
\text { Intervening }\end{array}$ & Indikator \\
\hline $\begin{array}{l}\text { Green } \\
\text { Management } \\
\left(\mathrm{Y}_{4}\right)\end{array}$ & & $\begin{array}{l}\text { Kedalaman Aktivitas Limbah Yang Dilakukan Untuk } \\
\text { Melestarikan Lingkungan (Pendekatan Legal) }\left(\mathrm{Y}_{4.1}\right) \\
\text { Kedalaman Aktivitas Limbah Yang Dilakukan Untuk } \\
\text { Melestarikan Lingkungan (Pendekatan Pasar) }\left(\mathrm{Y}_{4.2}\right) \\
\text { Kedalaman Aktivitas Limbah Yang Dilakukan Untuk } \\
\text { Melestarikan Lingkungan (Pendekatan Stakeholder) } \\
\left(\mathrm{Y}_{4.3}\right) \\
\text { Penghijauan SDM Mengerti Makna dan } \\
\text { Pengaplikasian Green (Efisiensi) }\left(\mathrm{Y}_{4.4}\right) \\
\text { Penghijauan Bahan Baku Yang Habis Digunakan } \\
\text { (Tidak Langsung Dibuang / Renewable) }\left(\mathrm{Y}_{4.5}\right)\end{array}$ \\
\hline $\begin{array}{l}\text { Keuangan } \\
\left(\mathrm{Y}_{3}\right)\end{array}$ & Pelanggan $\left(\mathrm{Y}_{2}\right)$ & $\begin{array}{l}\text { Pertumbuhan Pendapatan }(\mathrm{ROI})\left(\mathrm{Y}_{3.1}\right) \\
\text { Berkurangnya Biaya }\left(\mathrm{Y}_{3.2}\right)\end{array}$ \\
\hline $\begin{array}{l}\text { Pelanggan } \\
\left(\mathrm{Y}_{2}\right)\end{array}$ & $\begin{array}{l}\text { Proses } \\
\text { Bisnis / Intern } \\
\left(\mathrm{Y}_{1}\right)\end{array}$ & $\begin{array}{l}\text { Meningkatkan Kepercayaan Pelanggan }\left(\mathrm{Y}_{2.1}\right) \\
\text { Kecepatan Layanan }\left(\mathrm{Y}_{2.2}\right)\end{array}$ \\
\hline
\end{tabular}


Jurnal Teknologi dan Manajemen Industri, Vol. 3 No. 1, Februari 2017

Pascasarjana Institut Teknologi Nasional Malang

\begin{tabular}{|l|l|l|}
\hline $\begin{array}{l}\text { Proses } \\
\text { Bisnis }\end{array}$ & $\begin{array}{l}\text { Meningkatkan Kualitas Proses Layanan Customer } \\
\left(\mathrm{Y}_{1.1}\right) \\
\text { State Of The Art Technology }\left(\mathrm{Y}_{1.2}\right)\end{array}$ \\
\hline Pembelajaran & & $\begin{array}{l}\text { Employee Satisfaction }\left(\mathrm{X}_{1.1}\right) \\
\text { Employee Retention }\left(\mathrm{X}_{1.2}\right)\end{array}$ \\
& & $\begin{array}{l}\text { Employee Productivity }\left(\mathrm{X}_{1.3}\right) \\
\text { Motivasi }\left(\mathrm{X}_{1.4}\right)\end{array}$ \\
\hline Pertumbuhan & & Pemberdayaan Dan Keselarasan $\left(\mathrm{X}_{1.5}\right)$ \\
$\left(\mathrm{X}_{2}\right)$ & & Pertumbuhan Penjualan $\left(\mathrm{X}_{2.1}\right)$ \\
& Pertumbuhan Organisasi $\left(\mathrm{X}_{2.2}\right)$ \\
& Pertumbuhan Jaringan Network $\left(\mathrm{X}_{2.3}\right)$ \\
\hline
\end{tabular}

\section{Metode Penelitian}

Metodologi yang digunakan adalah kombinasi variabel Balance Scorecard, Green Management, dan Continous Improvement. Pengumpulan data menggunakan maximum likelihooddengan jumlah 100 responden [3], responden dalam penelitian iniadalahSupervisior (SPV), administrasi dan pengemudi yang fokus bekerja di Bidang Ekspansi Angkutan Limbah Koperasi XYZ. Analisis data dalam penelitian ini menggunakan Chi - Square Statistic $\left(X^{2}\right)$, The Root Mean Square Error Of Approximation (RMSEA), Comparative Fit Index (CFI), Tucker Lewis Index (TLI), Goodness of Fit Index (GFI) dan Adjusted Goodness of Fit Index (AGFI), dengan koefisien signifikan (p value) sebesar 5\%. 
Jurnal Teknologi dan Manajemen Industri, Vol. 3 No. 1, Februari 2017

Pascasarjana Institut Teknologi Nasional Malang

Berikut adalah diagram alir penelitian:

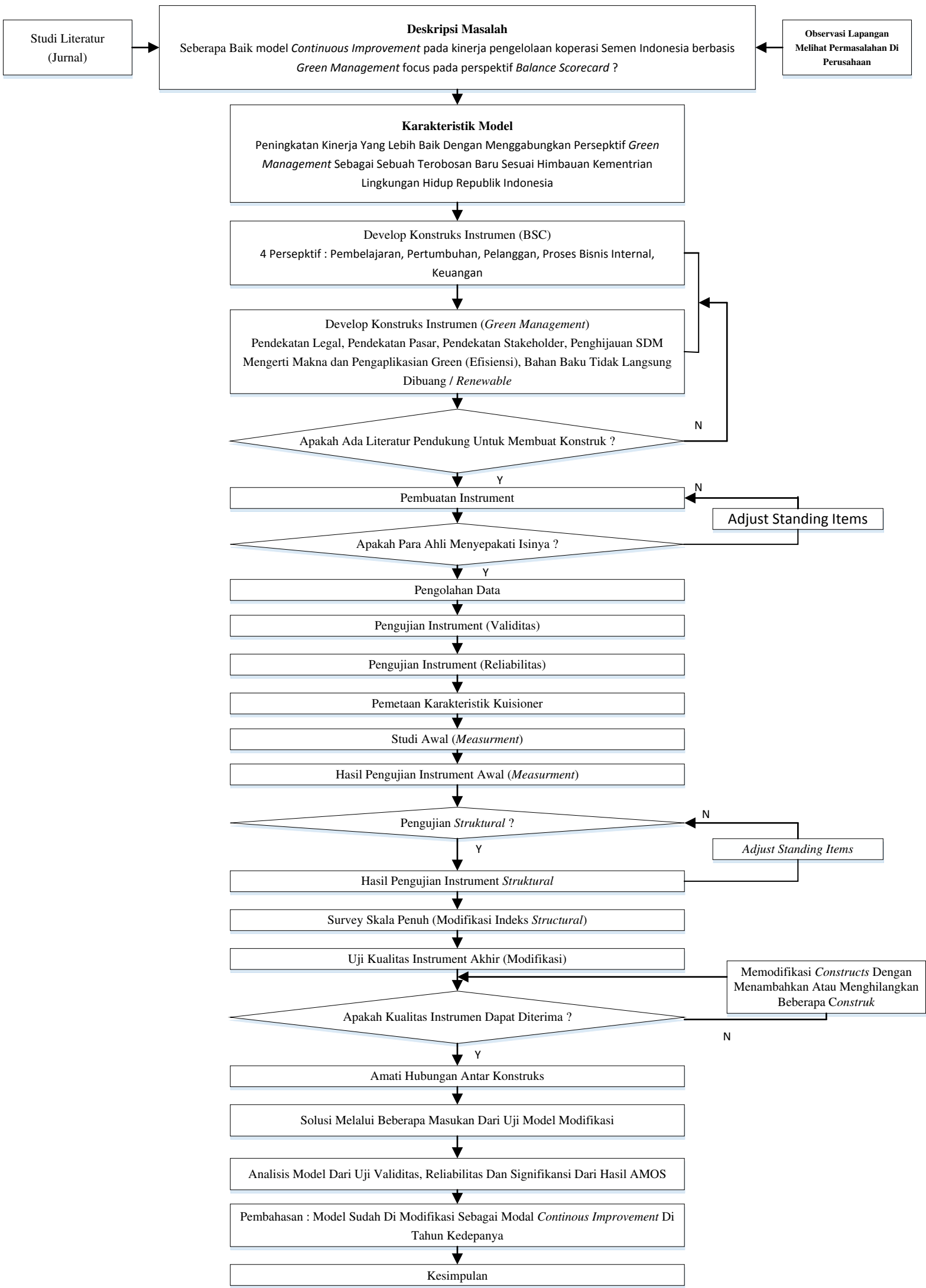

Gambar 1. Diagram Alir Penelitian 
Pada diagram alir Gambar 1, penelitian dimulai dari studi literatur dan observasi untuk mendukung dekskripsi masalah yang akan di teliti, kemudian merumuskan masalahnya untuk mengetahui pengaruh variabel balanced scorecard berbasis Green Management yang berkelanjutan (Continuos Improvement) yang disinergikan denganStructural Equation Modelling (SEM) sebagai sarana perencanaan strategi kedepan dalam proses bisnisnya.Langkah selanjutnya dalam penelitian ini adalah menyusun kuesioner, menyebarkan dan mengumpulkan hasil kuisioner untuk ditabulasikan dalam tabel frekuensi,sebelum melakukan analisis dengan SEM, terlebih dahulu dilakukan uji variabel untuk mengetahui koefisien validitas dan reliabilitas. Jika variabel penelitianvalid dan reliableselanjutnya membuat model konseptual yang terdiri dari measurment, structural dan modifikasi dengan developvariabel - variabel yang telah ditentukan(Observasi lapangan dan studi literatur). Dalam model measurmentdan structuralvariabel yang sudah ditentukan seperti gambar 2 memilikiperbedaan yakni pada garis,kalau measurment garisnya dengan anak panah 2 arah ( ) yang artinya adanya dua korelasi antar dua variabel, sedangkan structural garisnya dengan anak panah satu arah ( ) yang artinya menujukan hubungan regresi, sedangkanuntuk structural,jika nilaigoodness of fitkurang bagus maka harus dilakukan proses modifikasi.Pada prosesmodifikasi model gambarnya sama seperti structural bedannya kalau modifikasi merujuk pada nilai Modification Indeks (MI) dari structuraldengan mengambil nilaiterbesar dan harus berbasis teori, selanjutnyamenghubungan dengan garis anak panah dua arah. Analisa hasil output modifikasi dilakukan guna mendefinisikanmodel yang mengakomodasi perspektif BSC yang di sinergikan Green Management untuk memberikan gambaran identifikasi peningkatan perbaikan kinerja yang berkelanjutan (Continuos Improvement) di Koperasi XYZ.Berikut adalah hipotesis penelitian seperti dalam tabel 2.

Tabel 2. Hipotesis Penelitian

\begin{tabular}{|c|c|c|c|}
\hline Deskripsi & $\overline{\mathbf{H}_{0}}$ & $\mathbf{H}_{1}$ & Keputusan \\
\hline H-1 & $\begin{array}{l}\text { Proses pembelajarantidak } \\
\text { berpengaruh langsung dan } \\
\text { signifikan terhadap Proses } \\
\text { bisnis internal }\end{array}$ & $\begin{array}{l}\text { Proses pembelajaran } \\
\text { berpengaruh langsung } \\
\text { dan signifikan } \\
\text { terhadapProses bisnis } \\
\text { internal. }\end{array}$ & $\begin{array}{l}\text { Ho diterima karena C.R } \\
(1.691)>1.976 \\
\mathbf{H}_{\mathbf{1}} \text { ditolak karena C.R } \\
(\mathbf{1 . 6 9 1})<\mathbf{1 . 9 7 6}\end{array}$ \\
\hline H-2 & $\begin{array}{l}\text { Proses pertumbuhan tidak } \\
\text { berpengaruh langsung dan } \\
\text { signifikan terhadap Proses } \\
\text { bisnis internal. }\end{array}$ & $\begin{array}{l}\text { Proses pertumbuhan } \\
\text { berpengaruh langsung } \\
\text { dan signifikan terhadap } \\
\text { Proses bisnis internal. }\end{array}$ & $\begin{array}{l}\mathrm{H}_{\mathbf{1}} \text { diterima karena } \mathbf{C} . \mathbf{R} \\
(\mathbf{2 . 6 2 7})>\mathbf{1 . 9 7 6} \\
\mathrm{H}_{0} \text { ditolak karena C.R }(2.627) \\
<1.976\end{array}$ \\
\hline H-3 & $\begin{array}{l}\text { Proses bisnis internal tidak } \\
\text { berpengaruh langsung dan } \\
\text { signifikan terhadap } \\
\text { Pelanggan. }\end{array}$ & $\begin{array}{l}\text { Proses bisnis internal } \\
\text { berpengaruh langsung } \\
\text { dan signifikan terhadap } \\
\text { Pelanggan. }\end{array}$ & $\begin{array}{l}H_{1} \text { diterima karena } \mathbf{C R} \\
(\mathbf{4 . 7 6 5})>\mathbf{1 . 9 7 6} \\
\mathrm{H}_{0} \text { ditolak karena } \mathrm{CR}(4.765) \\
<1.976\end{array}$ \\
\hline $\mathrm{H}-4$ & $\begin{array}{l}\text { Pelanggan tidak } \\
\text { berpengaruh langsung dan } \\
\text { signifikan terhadap } \\
\text { Finansial. }\end{array}$ & $\begin{array}{l}\text { Pelanggan berpengaruh } \\
\text { langsung dan signifikan } \\
\text { terhadap Finansial. }\end{array}$ & $\begin{array}{l}\mathrm{H}_{1} \text { diterima karena } \mathrm{CR} \\
(\mathbf{4 . 8 7 3})>\mathbf{1 . 9 7 6} \\
\mathrm{H}_{0} \text { ditolak karena } \mathrm{CR}(4.873) \\
<1.976\end{array}$ \\
\hline H-5 & $\begin{array}{l}\text { Finansial tidak berpengaruh } \\
\text { langsung dan signifikan } \\
\text { terhadap perspektif Green } \\
\text { Management. }\end{array}$ & $\begin{array}{l}\text { Finansial berpengaruh } \\
\text { langsung dan signifikan } \\
\text { terhadap perspektif } \\
\text { Green Management. }\end{array}$ & $\begin{array}{l}\mathrm{H}_{1} \text { diterima karena CR } \\
(\mathbf{5 . 0 1 4})>\mathbf{1 . 9 7 6} \\
\mathrm{H}_{0} \text { ditolak karena } \mathrm{CR}(5.014)\end{array}$ \\
\hline
\end{tabular}




\begin{tabular}{l|l|l|l}
\hline & & & $<1.976$ \\
\hline
\end{tabular}

\section{Hasil Penelitian Dan Pembahasan}

Konstruksi model Continous Improvement pada pengelolaan Koperasi XYZ berbasis Green Management dengan perspektif Balance Scorecard mengalami 3 proses yakni measurment, structural dan modifikasi. Hasil measurement model belum menunjukan kriteria yang bagus karena nilai chi squaredari uji model $155.413<30.14353$ (Cut Off Value), untuk structural hanya probabilitas yang belum menunjukan kriteria bagus karena dari hasil uji model sebesar $0.000>0.05$ (Cut Off Value), agar nilai goodness of fit memenuhi syarat dilakukan modifikasi model dengan memperhatikan nilaiModification Indeks(MI) terbesar pada outputstrctural dengan memperhatikan dasar teori, dan hasil modifikasi modelnya sebagai berikut:

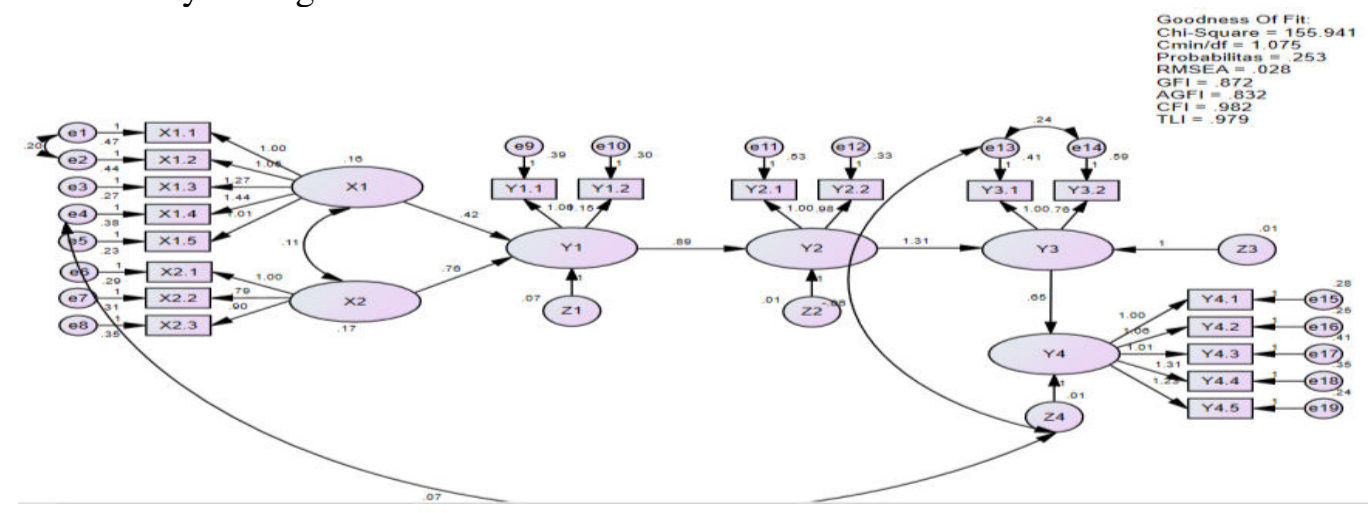

Gambar 2. Modifikasi Model

Untuk mendapatkan hasil uji modifikasi yang sesuai kriteria Goodness Of Fit peneliti melakukantrial and error dengan menghubungkan MI covarians dari output structural didapat nilaiterbesar ada pada variabel e13 lalu dihubungkan dengan e14 nilai MI sebesar 27.250, ternyata hasil good of fit belum memenuhi kriteria selanjutnya menghubungkan nilai MI covarians yang lain yakni e2 ke e1 dengan nilai MI sebesar 13.587, e4 ke z4 dengan nilai MI sebesar 11.081 dan e13 ke z4 dengan nilai MI sebesar 14.655 dan hasilnya memenuhi kriteria hasil untuk uji modifikasi model. Lihat gambar 2dan tabel 3.

Tabel3. Hasil Uji Model dan Cut Off Value(Modifikasi)

\begin{tabular}{l|l|l|l}
\hline Kriteria & Hasil Uji Model & Nilai Kritis & Keterangan \\
\hline$X^{2}$ Chi square & 155.941 & $\begin{array}{l}\text { Kecil, } \mathrm{X}^{2} \text { dengan } \mathrm{df}=147 \text { dengan } \alpha \\
=0,05 \text { adalah 176.2938 }\end{array}$ & Baik \\
\hline Probabilitas & 0.253 & $\geq 0,05$ & Baik \\
\hline RMSEA & 0.028 & $\leq 0,08$ & Baik \\
\hline GFI & 0.872 & $\geq 0,90$ & Marginal \\
\hline AGFI & 0.832 & $\geq 0,90$ & Marginal \\
\hline TLI & 0.979 & $\geq 0,95$ & Baik \\
\hline CFI & 0.982 & $\geq 0,95$ & Baik \\
\hline
\end{tabular}

Proses modifikasi dengan langkah - langkah yang sudah dilakukan dengan menggabungkan e13 ke e14, e2 ke e1, e4 ke z4 dan e13 ke z4 sudah menunjukan bahwasanya model dan hasil tersebut sudah sesuai Goodness of Fit yang sudah ditetapkan. 


\section{Hipotesis Pertama (H-1)}

$\mathrm{H}_{0}$ : Proses pembelajarantidak berpengaruh langsung dan signifikan terhadap Proses bisnis internal. $\mathrm{H}_{1}$ : Proses pembelajaran berpengaruh langsung dan signifikan terhadapProses bisnis internal.

Hasil : Proses pembelajaran $\left(\mathrm{X}_{1}\right)$ tidak berpengaruh langsung dan signifikan terhadap Proses Bisnis Internal $\left(\mathrm{Y}_{1}\right)$ sehingga $\mathrm{H}_{1}$ ditolak, tercermindari C.R $(1.691)<1.976$, untuk meningkatkan proses pembelajaran dan proses bisnis internal bisa melalui penambahan gaji, movitasi, pembekalan materi dan pendekatan intens agar bisa menunjang produktifitas kerjanya. Pembekalan motivasi berguna untuk meningkatkan pembelajaran kedisplinan dalam pekerjaan dan meningkatkan pembelajaran atas kemampuannya, ini tercermin dari hasil evaluasi data frekuensi kuesioner untuk interval tinggi belum optimal sehingga bisa ditingkatkan. Penelitian sejenis memperoleh hasil berbeda dengan nilai C.R (1.58) > 0.05 [4], jadi $\mathrm{H}_{1}$ diterima.

\section{Hipotesis $\operatorname{Kedua}(\mathrm{H}$ - 2)}

$\mathrm{H}_{0}$ : Proses pertumbuhan tidak berpengaruh langsung dan signifikan terhadap Proses bisnis internal.

$\mathrm{H}_{1}$ : Proses pertumbuhan berpengaruh langsung dan signifikan terhadap Proses bisnis internal.

Hasil : Proses pertumbuhan $\left(\mathrm{X}_{2}\right)$ berpengaruh langsungterhadap Proses Bisnis Internal $\left(\mathrm{Y}_{1}\right)$ sehingga $\mathrm{H}_{1}$ diterima, dimana implementasi di perusahaan optimal dan tercermin dalamnilai C.R $(2.627)>1.976$, dapat diartikan bahwa proses pertumbuhan dalam perusahaan harus dipertahankan dengan cara evaluasi rutin dan pembekalan wawasan dan motivasi kepada semua pekerjadalam rangka menambah nilai tambah yang akhirnya berorientasi pada pertumbuhan pendapatan, pertumbuhan dalam organisasi, dan pertumbuhan dalam jaringan network. Penelitian ini mendukung penelitan $[2,4,6]$

\section{Hipotesis Ketiga (H - 3)}

$\mathrm{H}_{0}$ : Proses bisnis internal tidak berpengaruh langsung dan signifikan terhadap Pelanggan.

$\mathrm{H}_{1}$ : Proses bisnis internal berpengaruh langsung dan signifikan terhadap Pelanggan.

Hasil : Proses bisnis internal berpengaruh langsungterhadap pelanggan sehingga $H_{1}$ diterima,dimana implementasi di perusahaan optimal dan tercerminpadaCR $(4.765)>1.976$, dapat diartikan bahwa proses bisnis internal sudah optimal dan harus ditingkatkan dengan carapembinaan, pembekalan, monitoring berkala dan pembaruan teknologi akan menghasilkan proses layanan pelanggan yang unggul. Penelitian ini mendukung dengan penelitan [4]

\section{Hipotesis Keempat (H- 4)}

$\mathrm{H}_{0}$ : Pelanggan tidak berpengaruh langsung dan signifikan terhadap Finansial.

$\mathrm{H}_{1}$ : Pelanggan berpengaruh langsung dan signifikan terhadap Finansial.

Hasil : Pelanggan berpengaruh langsung sehingga $\mathrm{H}_{1}$ diterima,dimana implementasi di perusahaan sudah optimal dan tercerminpadaCR $(4.873)>1.976$, dapat diartikan implementasi di perusahaan optimal dan harus dipertahankan dengan cara perencanaan strategi yang lebih matang agarpertumbuhan pendapatan (ROI) meningkatkan dan menyeimbangkan neraca finansial perusahaan agar berkurangnya biaya bisa ditekan. Penelitian ini mendukung penelitan $[4,5,6]$

\section{Hipotesis kelima (H-5)}

$\mathrm{H}_{0}$ : Finansial tidak berpengaruh langsung dan signifikan terhadap perspektif Green Management.

$\mathrm{H}_{1}$ : Finansial berpengaruh langsung dan signifikan terhadap perspektif Green Management.

Hasil : Finansial berpengaruh langsungsehingga $\mathrm{H}_{1}$ diterima,dimana implementasi di perusahaan juga sudah optimal dan tercerminpada di mana CR $(5.014)>1.976$, dapat diartikan bahwa apabila proses Green Management di perusahaan sudah optimal dan harus dipertahankan dengan cara lebih menekankan pada pendekatan legal, pendekatan pasar, SDM mengerti pengaplikasian Green, penghijauan bahan baku (Renewable). Belum ada penelitian terdahulu yang membahas peresepktif Finansial ke Green Management. 


\section{Kesimpulan}

\section{- Hasil Uji Modifikasi Model}

Hasil uji modifikasi model semua kriteria goodness of fit yang terdiri dari Chi Square, Probabilitas, RMSEA, GFI, AGFI dan TLI, dari semua pengujian memenuhi kriteria sehingga model pengukuran menjadi bagus.

\section{- Kesimpulan Yang Didapat}

Proses pembelajaran $\left(\mathrm{X}_{1}\right)$ tidak berpengaruh signifikan terhadap proses bisnis internal $\left(\mathrm{Y}_{1}\right)$,proses pertumbuhan $\left(\mathrm{X}_{2}\right)$ berpengaruh signifikan terhadap proses bisnis internal $\left(\mathrm{Y}_{1}\right)$, proses bisnis internal berpengaruh signifikan terhadap pelanggan,pelanggan berpengaruh signifikan terhadap finansial dan finansial berpengaruh signifikan terhadapGreen Management.

- Hasil Kesimpulan Hipotesis

Hasil penelitian ini menunjukan semua variabel berpengaruh signifikan kecuali variablepembelajaran $\left(\mathrm{X}_{1}\right)$ terhadap proses bisnis internal $\left(\mathrm{Y}_{1}\right)$. Dari hasil pengujian ini diharapkanmenjadi pegangan penting dalam melakukan improvementagar Koperasi XYZ tetap eksis dan selalu siap menghadapi persaingan Masyarakat Elonomi ASEAN (MEA) atau pun menghadapi persaingan businesslainnya.

\section{Daftar Referensi}

[1] Kaplan, R.S., R.D. Norton, 1996b. Using theBalanced Scorecard As a Strategic ManagementSystem, Harvard Business Review, pp.75-85.

[2] Ken Ogat, Gary Spraakman, 2014. Beyond Control: Using the Balanced Scorecard to Change Culture and Implement Strategy, Canadian Academic Accounting Association (CAAA) Annual Conference, pp.1-50.

[3] Tabachnick, B. G., \& Fidell, L.S (1996). Using Multivariate Statistics (Third ed). New York: Harpoer Collings College Publishers.

[4] Waluyo Minto, Noer Soejipto, 2015. Case Studies in Research: Analysis on Performance Model Using Balanced Score Card, Strategic Objective and Sustainable Competitive Advantage Synergized with SEM. Australian Journal of Basic and Applied Sciences, pp.229-240

[5] Wu H.Y, Constructing a Strategy Map for Banking Institutions With Key Performance Indicators of the Balanced Scorecard, Evaluation \& Program Planning 35 (3), 2012, pp.303320.

[6] Sangjae. Lee, Sung Bum Park, Gyoo Gun Lim, Using Balanced Scorecards For the Evauation of "Software-as-aService" Information \& Management, 2013, pp. 553-561. 